\title{
Highlight report: Mycotoxins as food contaminants in Africa-challenges and perspectives
}

\author{
Mohamed F. Abdallah ${ }^{1,2} \oplus \cdot$ Marthe De Boevre $^{1} \cdot$ Kris Audenaert $^{2} \cdot$ Geert Haesaert $^{2} \cdot$ Sarah De Saeger $^{1}$
}

Received: 23 March 2018 / Accepted: 6 April 2018 / Published online: 13 April 2018

c) Springer-Verlag GmbH Germany, part of Springer Nature 2018

In 2050, the world population is expected to amount to 9.8 people (DESA 2015). Especially on the African continent, the population is increasing. This fact causes a food challenge which has to be faced in a world with a shrinking arable land (partially being diverted to biofuel crops), with less and more expensive petroleum, increasingly limited supplies of water and nitrogen, and within a scenario of a rapidly changing climate, social unrest, and economic uncertainty. Crop production in developed countries is at its maximum. Therefore, the 50 million smallholder farms scattered throughout developing countries might be one of the only viable options to meet present and future food needs in the growth areas (Lowder et al. 2016). To face the food challenge, emphasis will have to be put on food safety, -diversity, -synergy, -recycling and the integration of agriculture with social processes that value community participation.

Throughout Africa, maize is a paramount staple food of 1.2 billion people accounting for $60 \%$ of dietary calories (FAOSTAT 2018). Maize-based diets are a major cause of food safety and insecurity. Maize is prone to infections by Fusarium and Aspergillus fungi producing the mycotoxins fumonisins and aflatoxins (Robertson-Hoyt et al. 2007). In addition, peanuts, another major cash crop, is often infected with Aspergillus with subsequent aflatoxin infestations (Dorner 2008). Infection of these crops with the abovementioned fungi not only reduces the amount of available food and adversely affects the worldwide trade of Africa, but the produced mycotoxins have deleterious health effects and a social impact for all end consumers as health and malnutrition are often interconnected in Africa. Despite the high

Mohamed F. Abdallah

mohamed.fathi@ugent.be

1 Laboratory of Food Analysis, Department of Bio-analysis, Faculty of Pharmaceutical Sciences, Ghent University, Ghent, Belgium

2 Department of Plants and Crops, Faculty of Bioscience Engineering, Ghent University, Ghent, Belgium incidence of mycotoxins and the causal relationship with cancer and other malignant diseases, farmers are mostly not aware of the mycotoxin issue (De Ruyck et al. 2015). As exposure to mycotoxins in smallholder farms is embedded in traditional agricultural and socio-economic concepts, its mitigation requires an interdisciplinary and trans-disciplinary approach to reach out to these communities and tackle the mycotoxin issue.

One fundamental challenge is to raise the public awareness regarding the possible health risk posed by mycotoxigenic fungi and their mycotoxins (Beyene et al. 2016; Magembe et al. 2016; Adekoya et al. 2017). A second challenge is the lack of equipped laboratories with advanced instruments beside the insufficient laboratory experience of young African researchers. To overcome these problems and to translate that from theory into practice, calls for proposals by national and international funding agencies to strengthen the capacity and expertise are needed. Such projects should include long-term goals to (1) realize "human" capacity building (2) conduct cutting-edge research directly related to the African environment, (3) transfer knowledge on several detection techniques, and (4) implement pre- and postharvest practices.

A last challenge is the need for regulations, with attention to the local food consumption patterns, for food and feed commodities that are destined for the local markets.

\section{References}

Adekoya I, Njobeh P, Obadina A et al (2017) Awareness and prevalence of mycotoxin contamination in selected nigerian fermented foods. Toxins (Basel) 9:363. https://doi.org/10.3390/toxins9110363

Beyene AA, Woldegiorgis AZ, Adish AA et al (2016) Assessment of mothers' knowledge and practice towards aflatoxin contamination in complementary foods in Ethiopia: from pre-harvest to household. World Mycotoxin J 9:535-544. https://doi.org/10.3920/ WMJ2016.2088

De Ruyck K, De Boevre M, Huybrechts I, De Saeger S (2015) Dietary mycotoxins, co-exposure, and carcinogenesis in humans: 
Short review. Mutat Res Mutat Res 766:32-41. https://doi. org/10.1016/J.MRREV.2015.07.003

DESA U (2015) World population projected to reach 9.7 billion by 2050 | UN DESA I United Nations Department of Economic and Social Affairs. In: UN Dep. Econ. Soc. Aff. https://www.un.org/ development/desa/en/news/population/world-population-prosp ects-2017.html. Accessed 7 Mar 2018

Dorner JW (2008) Management and prevention of mycotoxins in peanuts. Food Addit Contam Part A Chem Anal Control Expo Risk Assess 25:203-208. https://doi.org/10.1080/02652030701658357

FAOSTAT (2018) http://www.fao.org/faostat/en/\#data. Accessed 8 Mar 2018
Lowder SK, Skoet J, Raney T (2016) The number, size, and distribution of farms, smallholder farms, and family farms worldwide. World Dev 87:16-29. https://doi.org/10.1016/j.worlddev.2015.10.041

Magembe KS, Mwatawala MW, Mamiro DP, Chingonikaya EE (2016) Assessment of awareness of mycotoxins infections in stored maize (Zea mays L.) and groundnut (arachis hypogea L.) in Kilosa District, Tanzania. Int J Food Contam 3:12. https://doi.org/10.1186/ s40550-016-0035-5

Robertson-Hoyt LA, Betrán J, Payne GA et al (2007) Relationships among resistances to Fusarium and Aspergillus ear rots and contamination by fumonisin and aflatoxin in maize. Phytopathology 97:311-317. https://doi.org/10.1094/PHYTO-97-3-0311 